\title{
Evaluation of Se Accumulation in the Production of Se-treated Soybean Sprouts and Mungbean Sprouts
}

\author{
Hong Sook Bai ${ }^{1}$, Hyeong Soo $\mathrm{Kim}^{2}$, Sung Chul $\mathrm{Bai}^{3}$, and Dae Jin Kim ${ }^{1 \dagger}$ \\ ${ }^{1}$ Faculty of Food Science, Dong-A University, Busan 604-714, Korea \\ ${ }^{2}$ Dept. of Biomedical Laboratory Science, College of Biomedical Science and Engineering, \\ Inje University, Gyeongnam 621-749, Korea \\ ${ }^{3}$ Dept. of Aquaculture/FNRC, Pukyong National University, Busan 608-737, Korea
}

\begin{abstract}
In this study, the selenium (Se) accumulations of soybean sprouts and mungbean sprouts treated with various concentrations of Se-solutions were evaluated, as part of a broader effort to produce Se-enriched variants of the plants. Four levels of sodium selenate $\left(\mathrm{Na}_{2} \mathrm{SeO}_{4}\right)$-dissolved solutions (i.e. 0, T0; 6, T1; 60, T2; and $600 \mu \mathrm{g} / \mathrm{mL}$, T3) were prepared and sprayed onto the plants during cultivation. The effect of different spraying periods on Se accumulation was also assessed by watering plant groups once a day for periods of one, two, or three days. Se solution remaining on the surfaces of the plants was washed out by spraying with distilled water on the final day of cultivation. However, the increase of Se accumulation in the plants was found to depend on both Se-concentration and watering period, and the soybean sprouts were detemined to accumulate Se more effectively than the mungbean sprouts. Additionally, with regard to Se accumulation in the plants, the period of application of Se solution was detemined to be more important than the concentration of the Se solution applied. The averaged total levels of Se-enrichment in whole soybean sprouts at T0, T1, T2, and T3 were 0.26, 65.86, 179.62, and $525.12 \mathrm{\mu g} / \mathrm{dry}$ matter $(\mathrm{DM}) \mathrm{g}$, respectively, and the relative equations relating Se enrichment in soybean sprouts (Y) against watening days $(X)$ were $Y=32.505 X-36.17(T 1), Y=88.46 X-92.04$ (T2), and $Y=251.11 X-254.9$ (T3). The averaged total levels of Se-ennichment in the whole mungbean sprouts at T1, T2, and T3 group were $0.05,3.64$, and $101.43 \mu \mathrm{g} / \mathrm{DM} \mathrm{g}$, respectively, and the relative equations relating Se enrichment (Y) to watering days $(\mathrm{X})$ for mungbean sprouts were $\mathrm{Y}=1.67 \mathrm{X}-1.3467$ at $\mathrm{T} 1$ and $\mathrm{Y}=48.035 \mathrm{X}-46.907$ at $\mathrm{T} 2$. The results of this study suggest that soybean sprouts and mungbean sprouts enriched with bioavailable Se can be produced on a large scale by Se supplementation, allowing for the development of healthy functional foods such as Se-enriched mungbean sprout soups and salads, Se-enriched functional drink and food additives, and selenium tablets to promote health.
\end{abstract}

Key words: selenium, sodium selenate, se-enriched soybean sprouts, se-enriched mungbean sprouts

\section{INTRODUCTION}

Selenium (Se) is a component of glutathione peroxidase, a powerful antioxidase (1). Because Se has generally been recognized to play an essential role in human health, a variety of Se-enriched foods have been developed in Korea and elsewhere. In order to ensure that the Se with which a product is enriched is bio-available, inorganic Se must be converted into organic compound-bound Se. For example, by adding inorganic Se into a mushroom culture medium, to produce Se-enriched mushrooms, the inorganic Se transferred into the mushrooms had to be converted into organic Se (2); this is also the case in the production of Se-enriched products such as high calcium-enriched dropwort (3), Se-fortified green tea $(4,5)$, and Se-enriched pumpkins (6). However, the $7^{\text {th }}$ revised recommendation of daily Se intake for Korean adults (7) establishes $50 \mu \mathrm{g}$ as the recommended amount of daily Se intake, also stipulating a maximum allowance of $400 \mu \mathrm{g} / \mathrm{day}$. However, the reported daily Se intake for Koreans is $43 \mu \mathrm{g} /$ day, thus leaving a small shortfall between the reported daily Se intake and the suggested daily Se requirement (8). In response to this, the current study addresses the production of food materials enriched with bio-available Se food materials which could function as Se supplements.

Soybean sprouts and mungbean sprouts are rapidly and easily producible plants and can be grown almost anywhere. They are also both high in protein, vitamins, and minerals, and thus they have become widely distributed low-cost traditional foods $(9,10)$. Soybean sprouts have long been used as a conventional food, and

${ }^{\dagger}$ Corresponding author. E-mail: djkim@donga.ac.kr

Phone: +82-51-200-7532, Fax: +82-51-200-7535 
also used in a dried form for medicinal purposes, as is recorded in the 'HyangYakGuGupBang' a medical reference book, which was published during the Go-Jong kingdom of old Korea $(11,12)$. In the period during which beans become bean sprouts, several changes occur in their contents that are relevant to human nutrition. For example, digestibility increases, and the anti-nutrition, trypsin-inhibitory, and intestinal gas-producing activities decrease; additionally, mineral usability increases as the result of a reduction in phytic acid content $(13,14)$. The germing of beans leads to increases in fiber contents and vitamins such as thiamin, riboflavin, ascorbic acid, carotene, retinol, etc., due to the predominant processes of catabolism in the seed leaf and anabolism in the germinal pivot $(15,16)$. Like soybean sprouts, mungbean sprouts are also a good source of vitamins and minerals (17). Demand for soybean sprouts and mungbean sprouts increased parallel to an increase in population until the late 1980s, but has since declined as the consequence of environmental pollution, lifestyle and taste changes, and other factors (14). However, various soybean sprout products, including germaniumtreated soybean sprouts (18) and green tea-enriched soybean sprouts (19) have also been introduced. As 70\% of Korean territory consists of granite and basalt, the Se content of Korean soil is generally quite low (20) thus, Korean plants harbor relatively low Se content, and Korean Se intake is also relatively low. Therefore, an increase in the levels of Se in Korean foodstuff would clearly generate health benefits for many Koreans. In a previous report, it was shown that daily Se intake for Koreans was $43 \mu \mathrm{g}$, and that $70 \%$ of this was delivered from crop consumption (21), although approximately 50 $\sim 90 \%$ of Se in crops is lost during crop polishing processes (22). This insufficient Se intake, however, could be overcome by the production and provision of Se-enriched conventional public food materials, such as soybean sprouts.

As a component of the current efforts to produce Se-enriched foodstuffs, this study assessed the capability for Se accumulation in Se solution-treated soybean sprouts and mungbean sprouts, using various treatment levels and time periods.

\section{MATERIALS AND METHODS}

\section{Cultivation of soybean and mungbean}

Soybean and mungbean samples were obtained from the Youngnam National Plant Experiment Station, the Rural Development Administration (RDA), and farms in Gamnori, Sangdong, Gimhae, and Gyeongnam, and the sample beans were initially budded by $3 \mathrm{hr}$ of soaking in distilled water. After budding, the beans were placed in an automated cultivator and then cultivated for 4 days with a watering pattern of $5 \mathrm{~min}$ of spraying per every 25 min interval, at room temperature. In order to cultivate Se-enriched soybean sprouts and mungbean sprouts, four different concentrations of Se solutions $(0,6,60$, $600 \mu \mathrm{g} / \mathrm{mL}$ ) were prepared by dissolving $0,6,60$, and $600 \mathrm{mg}$ of sodium selenate $\left(\mathrm{Na}_{2} \mathrm{SeO}_{4}\right.$, Sigma-Aldrich, MO, USA) into one liter of distilled water; these groups were designated as groups T0, T1, T2, and T3, respectively. The application of Se-solution to the plants was conducted by spraying the solution, in lieu of water, once daily for 1,2 , or 3 days from the $1^{\text {st }}$ day of the cultivation period. Se solution remaining on the surfaces of the plants was washed off with sprayed distilled water during the remaining days of cultivation. The applied experimental protocol of Se solution is provided in Table 1. 50 of those cultivated bean sprout samples were individually harvested in triplicate per group, after which the sample was freeze-dried and ground by part (seed leaf, germinal pivot, root, and whole plant) for further analyses, including Se content and dry matter measurements.

\section{Estimation of weight change of soybean sprouts}

As previously described, those 50 individuals of seed leaf, germinal pivot, and root of harvested soybean sprouts were weighed to up to two decimal points in triplicate, and their mean values were summed in order to determine the whole plant weight.

\section{Estimation of Se contents}

Samples were freeze-dried and ground with a $0.5 \mathrm{~mm}$ grinder. $3 \mathrm{~g}$ of ground samples were carefully positioned in a flask containing $10 \mathrm{~mL}$ of $50 \%$ aqueous nitric acid $\left(\mathrm{HNO}_{3}, \mathrm{v} / \mathrm{v}\right)$ and digested by heating the flask for $3 \sim 4$ hours until the solution became clear. Then, an appropriate volume of $\mathrm{H}_{2} \mathrm{O}_{2}$ solution was added to the flask in order to completely redigest the sample. The digested sample was reconstituted to a volume of $5 \mathrm{~mL}$, and the Se content in the sample was analyzed. Se contents in the analyzed bean sprouts were measured via ICP-MS (Perkin-Elmer 6100, USA) under operational conditions of $1.5 \mathrm{~kW} \mathrm{Rf}$ power and a sample flow rate of 100 $\mu \mathrm{L} / \mathrm{min}$, using $\mathrm{Ar}$ as a carrier.

\section{Statistical analysis}

All data were analyzed using Microsoft Excel (Microsoft Office 2003) to evaluate the effects of applied concentrations of Se solution on Se contents in the bean sprouts. When a significant treatment effect was observed, a Least Significant Difference (LSD) test was 
Table 1. The experimental protocol of Se solution treatment

\begin{tabular}{|c|c|c|c|c|}
\hline Treatment & $\begin{array}{c}\text { Concentration of } \\
\text { Se solution }(\mu \mathrm{g} / \mathrm{mL})\end{array}$ & $\begin{array}{c}\text { Treated } \\
\text { periods (days) }\end{array}$ & $\begin{array}{l}\text { Sprayed volume of } \\
\text { Se solution (L) }\end{array}$ & $\begin{array}{c}\text { Amount of } \\
\text { Se applied (mg) }\end{array}$ \\
\hline T0 & 0 & 3 & - & - \\
\hline $\mathrm{T} 1$ & 6 & $\begin{array}{l}1 \\
2 \\
3\end{array}$ & $\begin{array}{l}2.5 \\
5.0 \\
7.5\end{array}$ & $\begin{array}{l}15 \\
30 \\
45\end{array}$ \\
\hline $\mathrm{T} 2$ & 60 & $\begin{array}{l}1 \\
2 \\
3\end{array}$ & $\begin{array}{l}2.5 \\
5.0 \\
7.5\end{array}$ & $\begin{array}{l}150 \\
300 \\
450\end{array}$ \\
\hline T3 & 600 & $\begin{array}{l}1 \\
2 \\
3\end{array}$ & $\begin{array}{l}2.5 \\
5.0 \\
7.5\end{array}$ & $\begin{array}{l}1500 \\
3000 \\
4500\end{array}$ \\
\hline
\end{tabular}

T0, T1, T2, and T3 in the "treatment" column indicate the levels of administered Se solutions which are 0, 6, 60, and 600 $\mu \mathrm{g} / \mathrm{mL}$, respectively, as described in the "concentration of Se solution" column. The numbers in the "treated periods" column designate only the numbers of days on which Se solution was administered; thus, the remaining days of DW spraying during the 4 days of cultivation are not addressed in this figure.

used to compare means. The effects of treatment were considered statistically significant at $\mathrm{p}<0.05$.

\section{RESULTS AND DISCUSSION}

\section{Measurement of soybean sprouts weight}

The weights of the Se-enriched soybean sprouts are shown in Table 2. We noted no differences in the total weight changes of the cotyledon, hypocotyl, and root among the treatment groups. The total weights of soybean sprouts within the T3 groups (T3-1, T3-2, and T3-3 as $28.47 \mathrm{~g}, 26.10 \mathrm{~g}$, and $24.83 \mathrm{~g}$, respectively), when compared to T0, also showed that there was no statistical difference (Table 2). However, Yun et al. (23) previously determined that the weights of produced lettuce and crown daisy were $33.9 \mathrm{~g}$ and $22.3 \mathrm{~g}$ when treated with high concentrations of sodium selenate $(16 \mu \mathrm{g} / \mathrm{mL})$; these treated samples were lighter than the non-Se treated products: $58.1 \mathrm{~g}$ for untreated lettuce and $73.1 \mathrm{~g}$ for untreated crown daisy. One possible reason for this was suggested by Lauchli (24), who held that the functioning of Se-contained protein was not appropriate for the growth of these plants, due to an alteration in the protein structure-namely, Se and S may be competitively absorbed by plants and the absorption of Se would result in a preference of selenocysteine synthesis over cysteine synthesis.

\section{Estimation of Se accumulation in soybean sprouts}

As is shown in Table 3, Se content in soybean sprouts increased gradually when the Se treatment concentration was increased. For example, when those Se solutions were administered for three days, the Se levels in the soybean sprouts were measured at $0.26,65.86,179.62$, and $525.12 \mu \mathrm{g} / \mathrm{DM} \mathrm{g}$ in the T0, T1, T2, and T3 groups, respectively. The increase in Se concentration in these plants was 3.3 to 2019 that of the T0 group, corresponding to increases in the concentration of Se solution from 6 to $600 \mu \mathrm{g} / \mathrm{mL}$. This suggests that the Se-enrichment increased in the plants subjected to Se solution treatment in a concentration-dependent manner. However, the period of Se solution treatment was determined to be more

Table 2. Weights of Se-treated soybean sprouts and production indices

\begin{tabular}{cccccc}
\hline Group & Cotyledon (g/50 plants) & Hypocotyl (g/50 plants) & Root (g/50 plants) & Total (g/50 plants) & Production index \\
\hline T0 & $15.37 \pm 1.80$ & $13.27 \pm 1.56$ & $3.93 \pm 0.42$ & $32.57 \pm 3.75$ & 100 \\
T1-1 & $14.43 \pm 0.38$ & $14.27 \pm 0.59$ & $2.70 \pm 0.17$ & $31.40 \pm 1.08$ & 97 \\
T1-2 & $14.17 \pm 0.31$ & $12.57 \pm 1.43$ & $3.83 \pm 0.38$ & $30.57 \pm 2.05$ & 94 \\
T1-3 & $14.83 \pm 0.45$ & $13.23 \pm 1.10$ & $2.77 \pm 0.67$ & $30.57 \pm 1.55$ & 94 \\
T2-1 & $14.47 \pm 0.40$ & $12.27 \pm 0.32$ & $3.93 \pm 0.25$ & $30.67 \pm 0.95$ & 94 \\
T2-2 & $15.63 \pm 0.40$ & $15.60 \pm 1.21$ & $2.73 \pm 0.67$ & $33.96 \pm 1.25$ & 104 \\
T2-3 & $14.30 \pm 0.35$ & $12.90 \pm 0.53$ & $2.93 \pm 0.38$ & $34.16 \pm 0.55$ & 105 \\
T3-1 & $13.87 \pm 0.12$ & $12.47 \pm 0.35$ & $2.13 \pm 0.40$ & $28.47 \pm 0.35$ & 87 \\
T3-2 & $13.67 \pm 0.15$ & $10.90 \pm 0.26$ & $1.53 \pm 0.06$ & $26.10 \pm 0.30$ & 80 \\
T3-3 & $14.63 \pm 0.15$ & $9.47 \pm 0.40$ & $0.73 \pm 0.12$ & $24.83 \pm 0.57$ & 76 \\
\hline
\end{tabular}

The "group" refers to the concentration of Se in the treatment solution and the watering period is listed (in days) after the hyphen, as shown in Table 1. Shown values are mean \pm SD of 50 samples in triplicate. The production index is the calculated relative value, based on the total weight of the T0 group as 100 . 
Table 3. Se accumulation in soybean sprouts ( $\mu \mathrm{g} / \mathrm{DM} \mathrm{g}$ )

\begin{tabular}{ccrc}
\hline Group & Cotyledon & Hypocotyl & \multicolumn{1}{c}{ Total } \\
\hline T0 & $0.05 \pm 0.00$ & $2.15 \pm 0.01$ & $0.26 \pm 0.00$ \\
T1-1 & $0.59 \pm 0.00^{\mathrm{a}}$ & $1.77 \pm 0.01^{\mathrm{a}}$ & $0.85 \pm 0.01^{\mathrm{a}}$ \\
T1-2 & $2.94 \pm 0.02^{\mathrm{b}}$ & $104.63 \pm 0.94^{\mathrm{b}}$ & $19.81 \pm 0.09^{\mathrm{b}}$ \\
T1-3 & $5.99 \pm 0.04^{\mathrm{c}}$ & $333.90 \pm 2.33^{\mathrm{c}}$ & $65.86 \pm 0.34^{\mathrm{c}}$ \\
T2-1 & $2.59 \pm 0.01^{\mathrm{a}}$ & $7.29 \pm 0.05^{\mathrm{a}}$ & $2.70 \pm 0.01^{\mathrm{a}}$ \\
T2-2 & $19.83 \pm 0.07^{\mathrm{b}}$ & $312.77 \pm 1.67^{\mathrm{b}}$ & $72.32 \pm 0.43^{\mathrm{b}}$ \\
T2-3 & $44.11 \pm 0.21^{\mathrm{c}}$ & $1366.61 \pm 3.26^{\mathrm{c}}$ & $179.62 \pm 1.08^{\mathrm{c}}$ \\
T3-1 & $15.98 \pm 0.11^{\mathrm{a}}$ & $43.24 \pm 0.19^{\mathrm{a}}$ & $22.90 \pm 0.12^{\mathrm{a}}$ \\
T3-2 & $114.78 \pm 0.97^{\mathrm{b}}$ & $839.05 \pm 2.02^{\mathrm{b}}$ & $193.94 \pm 1.31^{\mathrm{b}}$ \\
T3-3 & $252.44 \pm 1.74^{\mathrm{c}}$ & $1808.96 \pm 4.09^{\mathrm{c}}$ & $525.12 \pm 3.27^{\mathrm{c}}$
\end{tabular}

The "group" indicates the treated level of Se solution and the watering period is listed after the hyphen as shown in Table 1 . Shown values are mean \pm SD of Se which are measured by ICP-MS, in three pooled samples of soybean sprouts based on one gram of dry matter (DM). The replicated analytic error within the samples of same batch was accepted when less than 0.0001 . Those statistical analyses presented with superscribed alphabets indicate the difference within the same group at $\mathrm{p}<0.05$.

effective for Se accumulation in the plants. As is shown in Fig. 1, the difference in Se accumulation between the groups was increased with increases in the watering period. The putative relationship between the watering period and Se accumulation in the plants is shown in Fig. 1, and the relative equations were $y=32.505 x-$ 36.17 for $\mathrm{T} 1, \mathrm{y}=88.46 \mathrm{x}-92.04$ for $\mathrm{T} 2$, and $\mathrm{y}=251.11 \mathrm{x}$ -254.9 for T3, in which y represents the enriched concentration of Se in soybean sprouts and $x$ represents the days of Se treatment. Another study (25) involving the administration of $\mathrm{SeCO}_{2}$ solution to soybean sprouts also showed that the frequencies of 'the $1 \mathrm{hr}$ soaking and $7 \mathrm{hr}$ non-soaking process' for 5 days increased Se-enrichment in the plants, but their observed values were substantially lower than our own, and the method of

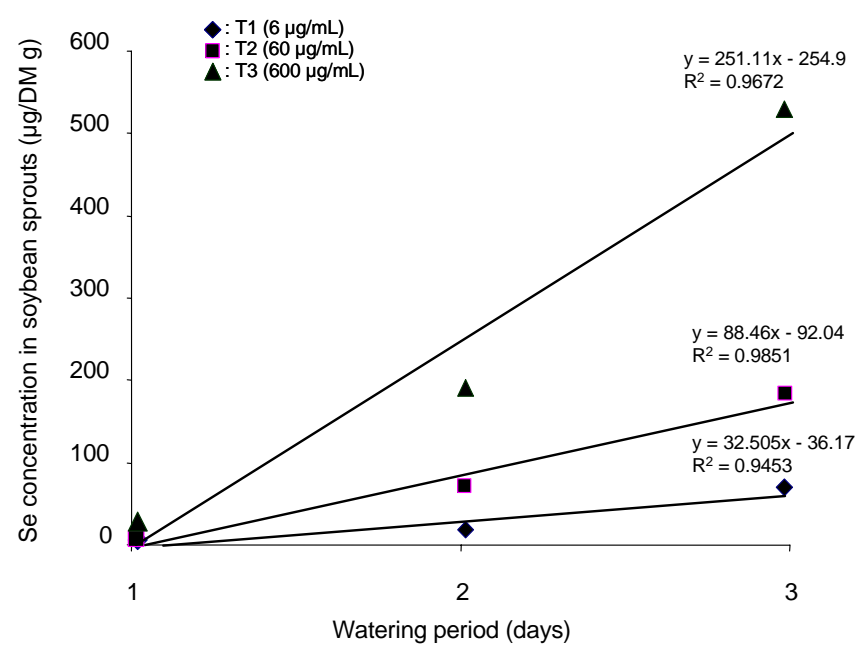

Fig. 1. Se accumulation in soybean sprouts during the watering days. Shown data refer to Table 3. DM represents dry matter.
Table 4. Change of Se contents in mungbean sprouts

$(\mu \mathrm{g} / \mathrm{DM} \mathrm{g})$

\begin{tabular}{cc}
\hline Treatment & Total \\
\hline T0 & $0.05 \pm 0.00$ \\
T1-1 & $0.30 \pm 0.00^{\mathrm{a}}$ \\
T1-2 & $2.04 \pm 0.01^{\mathrm{b}}$ \\
T1-3 & $3.64 \pm 0.01^{\mathrm{c}}$ \\
T2-1 & $5.36 \pm 0.02^{\mathrm{a}}$ \\
T2-3 & $40.70 \pm 0.35^{\mathrm{b}}$ \\
\hline
\end{tabular}

The "group" indicates the treatment level of Se solution and the watering period follows the hyphen, as shown in Table 1. Shown values are mean \pm S.D. of Se which are measured by ICP-MS, in three pooled samples of mungbean sprouts based on one gram of dry matter (DM). The replicated analytic error within the samples of same batch was accepted when less than 0.0001 . Those statistical analysis presented with superscribed alphabets indicate the difference within the same group at $\mathrm{p}<0.05$.

Se-treatment administered in the current study was also more effective, as well as much simpler.

\section{Estimation of Se accumulation in mungbean sprouts}

The values of Se accumulation in whole mungbean sprouts with different levels of Se solution treatment and different treatment periods are provided in Table 4. Like those soybean sprouts, total Se accumulation in mungbean sprouts increased with increases in the level of Se solution administered. In comparison to T0, the Se-enrichment in mungbean sprouts was increased from 6- to 73-fold in the T1 groups and 107- to 2029-fold in the T2 groups as the level of administered Se solution increased from 6 to $60 \mu \mathrm{g} / \mathrm{mL}$. The results indicated that the observed increase in Se accumulation in the mungbean sprouts was also dependent on both the level of treated Se solution and the Se solution treatment period. As is shown in Fig. 2, the extent of total Se accumulation in mungbean sprouts increased with increasing concentrations of administered Se solution. The correlation of Se-enrichment versus Se-treated period in the current observation can be expressed via the equations for the T1 and T2 groups in Fig. 2, which were $y=1.67 x-1.3467$ and $y=48.035 x-46.907$, respectively, in which y represents the concentration of enriched Se in the plants and $\mathrm{x}$ represents the days of treatment with Se solution.

\section{The effects of Se-treatment on Se accumulation in the plants}

Fig. 3 shows a comparison of Se accumulation by the level of treated Se concentration and the period of Se treated days in both soybean sprouts and mungbean sprouts. According to our results, the period of Se solution treatment appears to be more important and more effective in inducing Se accumulation in the plants, al- 


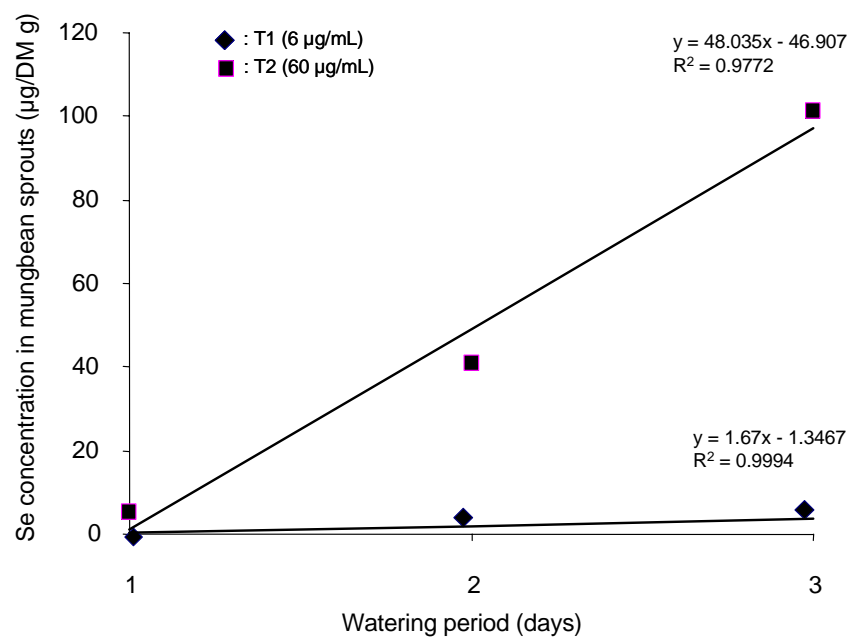

Fig. 2. Changes of Se-enrichment in mungbean sprouts. Shown data refer to Table 4. DM represents dry matter.

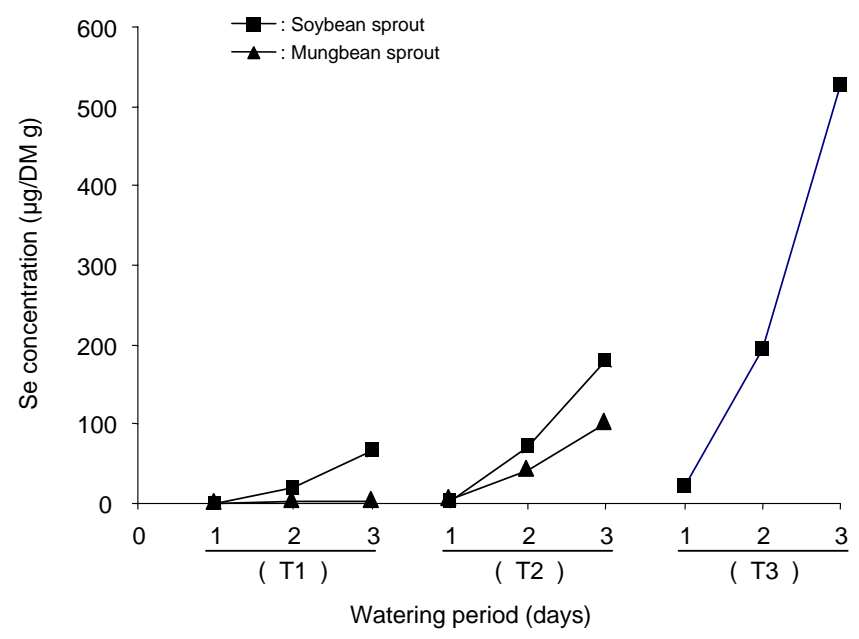

Fig. 3. The comparisons of Se accumulation in the plants. The presented data refer to Table 3 and 4. DM represents dry matter. The bracketed $\mathrm{T} 1, \mathrm{~T} 2$, and $\mathrm{T} 3$ in the figure represent the treatment group, as in Table 1.

though the concentration of administered Se solution is also important. This is illustrated by the finding that the observed difference in Se accumulation between the T1 and T3 (or T2 in mungbean sprouts) groups after one day of treatment was dwarfed by the differences in Se accumulation between the groups after 3 days of treatment. It remains to be definitively determined why Se accumulation was lower with shorter treatment periods, even when high levels of Se solution were administered, but it may be that the plants have only a limited daily capacity for Se absorption and storage. The results shown also demonstrate that soybean sprouts accumulated Se more effectively than the mungbean sprouts. Se has been shown to be absorbed to a relatively higher degree by Cruciferae and Legume species (26): the Se contents, for example, in Korean leguminous spe- cies such as sweet clover, lespedga, and landino clover have been measured at $86,40,25 \mu \mathrm{g} / \mathrm{DM}$ g, values that are generally higher than are observed in other plants (27). In the current study, relatively higher degrees of Se-enrichment were also observed in the soybean sprouts as compared to the mungbean sprouts, particularly in the T3 groups treated for 3 days with Se solution, with Se levels of 179.62 and $101.43 \mu \mathrm{g} / \mathrm{DM}$ g, respectively. This difference in the observed Se-enrichment levels between the species might be attributable to constitutional differences between the two. According to the $6^{\text {th }}$ Revised Table of Food Ingredients (28), $100 \mathrm{~g}$ of dry matter-based soybeans contains 39.82, 19.58, and $33.77 \mathrm{~g}$ of protein, fat, and carbohydrates, respectively, but the same quantity of mungbeans contains 24.53 g protein, $1.65 \mathrm{~g}$ fat, and $68.2 \mathrm{~g}$ carbohydrates. This may indicate that higher quantities of protein in the soybean would result in increased Se-enriched production, and this effect may be attributable to the accumulative synthesis of Se-enriched forms of proteins, such as selenomethionine and selenocysteine, in the plant (29).

\section{ACKNOWLEDGEMENT}

This paper was supported by the Dong-A University Research Fund in 2007.

\section{REFERENCES}

1. Levander OA, Burk RF. 1994. Selenium. In Modern nutrition in health and disease. 8th ed. Olson JA, Shike M, eds. Lea \& Febiger, Philadelphia.

2. Lee SH, Kuak WS, Kim WY. 2005. Studies on the selenium type and metabolism of selenium accumulation in the selenium-enriched mushroom. Korean J Anim Sci Technol 47: 305-316.

3. Pack KH. 2004. Cultivating method for high content of calcium dropwort containing selenium. The Republic of Korea the Industrial Property Office Patent No: 0444653.

4. Dong-A University. 2003. The cultivation method of green tea contained an organic selenium. The Republic of Korea the Industrial Property Office Patent No: 0523759.

5. Kim DJ, Chung DS, Bai SC, Kim HS, Lee YB. 2007. Effects of soil selenium supplementation level on selenium contents of green tea leaves and milk vetch. $J$ Korean Soc Food Sci Nutr 12: 35-39.

6. Kim HC. 2004. The pumpkin contained selenium. The Republic of Korea the Industrial Property Office Application NO: 10-2004-0038939.

7. The Korean Nutrition Society. 2005. Dietary reference intakes for Korean. Seoul. Korea. p 3-409.

8. Yang HR. 2003. Study of the dietary selenium intake and selenium status of Korean women. PhD Dissertation. Dankook University.

9. Park WK. 1991. Encyclopedia of foods and food science. Shinkwang publishing Corporation, Seoul. p 403-404.

10. Kim SD, Kim SH, Hong EH. 1993. Composition of soybean sprout and its nutritional value. J Korean Soybean 
Res 10: 1-9.

11. Jang GH. 1993. The history on food preparation and processing of Korean soybean used foods. Soohagsa, Seoul. p 198-232.

12. Kim EJ, Lee KI, Park KY. 2002. Quantity analysis of nutrients in soybean sprouts cultured with germanium. $J$ Korean Soc Food Sci Nutr 31: 1150-1154.

13. Shin YS. 1998. Changes in total lipid contents and the composition of fatty acids \& tocopherols during soybean sprouting. MS Thesis. Donga University, Korea. p 1-2.

14. Kim WJ, Kim NM, Sung HS. 1984. Effect of germination on phytic acid and soluble minerals in soymilk. Korean J Food Sci Technol 16: 358-362.

15. Kim EJ, Lee KI, Park KY. 2002. Effects of germanium treatment during cultivation of soybean sprouts. $J$ Korean Soc Food Sci Nutr 31: 615-620.

16. Hofsten B. 1979. Legume sprout as a protein and other nutrients. J Am Oil Chemists Soc 56: 382-392.

17. Choi IH, Kim SO, Kim KS, Lee MY. 1998. Effect of mungbean sprouts juice on cadmium-induced hepatotoxicity in rats. J Korean Soc Food Sci Nutr 27: 980-986.

18. Pack KY. 2002. Effects of germanium treatment during cultivation of soybean sprouts. J Korean Soc Food Sci Nutr 31: 615-620.

19. Pack YL. 2001. A manufacturing method of green-tea's bean-sprouts using a green-tea powder and a green-tea's bean-sprouts by it's manufacturing method. The Republic of Korea the Industrial Property Office Patent No: 0443262 .

20. Oh SH, Cho MY. 1983. Distribution of selenium contents in human blood and foods produced in Korea. Korean $J$ Nutr 16: 185-192.

21. Combs GF, Combs SB. 1986. The role of selenium in nutrition. Academic Press, Orlando.

22. Robinson MT, Thomson CD. 1984. Status of the food supply and residents of New Zealand. In Selenium in Biology and Medicine. Combs GF, ed. AVI Van Nostrand, New York. p 631-644.

23. Yun HK, Kim YC, Seo TC, Lee SG, Suh HD, Lee JG, Lee SH. 2003. Effect of selenium source and concentration on growth and quality of leafy lettuce and garland chrysanthemum in deep flow culture. $J$ Kor Soc Hort Sci 44: 447-450.

24. Lauchli, A. 1993. Selenium in plants: Uptake. function and environmental toxicity. Bot Acta 106: 455-468.

25. Han KH. 2003. The cultivation method of soybean sprouts and liquid composite contained selenium. The Republic of Korea he Industrial Property Office Application No: 10-2003-0086581.

26. Gunnaar GN, Umesh CG, Michel L, Tuomas W. 1985. Selenium in soil and plants and importance in livestock and human nutrition. Adv Agron 37: 397-468.

27. Rhee BW. 1970. Determination of selenium and copper in feedstuffs by radioactivation analysis. MS Thesis. Konkook University, Korea.

28. National Rural Living Science Institute. 2001. Food composition table 6th. p 120, 140.

29. Finley JW. 2005. Selenium accumulation in plants foods. Nutr Rev 63: 196-202.

(Received April 14, 2009; Accepted May 11, 2009) 